\title{
Correction to: Combination of photodynamic therapy (PDT) and anti- tumor immunity in cancer therapy
}

\author{
Hee Sook Hwang ${ }^{1} \cdot$ Heejun Shin ${ }^{1} \cdot$ Jieun $\mathrm{Han}^{1} \cdot \mathrm{Kun} \mathrm{Na}^{1}$ \\ Published online: 30 October 2018 \\ (c) The Author(s) 2018

\section{Correction to: Journal of Pharmaceutical Investigation (2018) 48:143-151} \\ https://doi.org/10.1007/s40005-017-0377-x
}

The article "Combination of photodynamic therapy (PDT) and anti-tumor immunity in cancer therapy", written by Hee Sook Hwang, Heejun Shin, Jieun Han and Kun Na, was originally published electronically on the publisher's internet portal (currently SpringerLink) on 14 December 2017 without open access.

With the authors' decision to opt for Open Choice the copyright of the article changed on 30 October 2018 to $($ ) The Author(s) 2017 and the article is forthwith distributed under the terms of the Creative Commons Attribution 4.0
International License (http://creativecommons.org/licenses/ by/4.0/), which permits use, duplication, adaptation, distribution and reproduction in any medium or format, as long as you give appropriate credit to the original author(s) and the source, provide a link to the Creative Commons license and indicate if changes were made.

The original article can be found online at https://doi.org/10.1007/ s40005-017-0377-x.

Kun Na

kna6997@catholic.ac.kr

1 Department of Biotechnology, The Catholic University

of Korea, 43 Jibong-ro, Wonni-gu, Bucheno-si,

Gyeonggido 14662, South Korea 